\title{
PENGARUH RISIKO KREDIT TERHADAP PROFITABILITAS PADA PT. BANK RAKYAT INDONESIA TBK PERIODE 2012-2019
}

\author{
Diana Maryana ${ }^{1}$, Wahyu Deni Widiastuti ${ }^{2}$ \\ Prodi D3 Akuntansi Politeknik Pos Indonesia ${ }^{1}$ \\ Email : dianamaryana@poltekpos.ac.id \\ Prodi D3 Akuntansi Politeknik Pos Indonesia ${ }^{2}$ \\ Email : wahyudeni75@gmail.com
}

\begin{abstract}
ABSTRAK
Perbankan dalam meningkatkan kinerja keuangan dengan menggunakan profitabilitas. Profitabilitas merupakan kemampuan bank memperoleh laba selama beberapa periode. Sehingga bank selalu berusaha untuk menghindari risiko dalam pemberian kredit karena akan menurunkan nilai profitabilitas. Tujuan dari penelitian ini adalah untuk mengetahui risiko kredit, mengetahui profitabilitas dan pengaruh risiko kredit terhadap profitabilitas pada PT. Bank Rakyat Indonesia Tbk periode 20122019.

Jenis penelitian ini menggunakan metode deskriptif dan asosiatif. Jenis data yang digunakan adalah data sekunder dengan metode pengumpulan dokumen dan studi kepustakaan. Teknik analisis yang digunakan adalah analisis kuantitatif dengan perhitungan analisis regresi linier sederhana, uji analisis korelasi product moment, analisis koefisien determinasi dan uji t.

Hasil penelitian menunjukkan bahwa: pertama, Risiko kredit PT. Bank Rakyat Indonesia Tbk tahun 2012-2019 mengalami fluktuasi. Hal ini dikarenakan kenaikan pada kredit macet yang terus meningkat. Kedua, Profitabilitas pada PT. Bank Rakyat Indonesia Tbk rata-rata pertahun cenderung mengalami penurunan, kecuali tahun 2018 mengalami peningkayan. Hal tersebut dikarenakan adanya penurunan kinerja laba sebelum pajak dan tingginya kredit macet. Ketiga, berdasarkan hasil uji t, disimpulkan bahwa adanya pengaruh negatif dan signifikan risiko kredit terhadap profitabilitas pada PT. Bank Rakyat Indonesia Tbk periode 2012-2019.
\end{abstract}

Kata kunci: Risiko Kredit (Non Performing Loan), Profitabilitas (Return On Asset)

\begin{abstract}
Banking in improving financial performance by using profitability. Profitability is the bank's ability to earn profits over several periods. So that banks always try to avoid risks in providing credit because it will reduce the value of profitability. The purpose of this study was to determine credit risk, to determine profitability and the effect of credit risk on profitability at PT. Bank Rakyat Indonesia Tbk for the period 2012-2019.

This type of research uses descriptive and associative methods. The type of data used is secondary data with document collection methods and literature study. The analysis technique used is quantitative analysis with the calculation of simple linear regression analysis, product moment correlation analysis test, determination coefficient analysis and t test.

The results showed that: first, the credit risk of PT. Bank Rakyat Indonesia Tbk in 2012-2019 experienced fluctuations. This is because the increase in bad credit continues to increase. Second, Profitability at PT. Bank Rakyat Indonesia Tbk tends to experience a decline annually on average, except in 2018 experiencing an increase. This is due to a decline in earnings before tax and high bad debts. Third, based on the results of the t test, it is concluded that there is a negative and significant effect of credit risk on profitability at PT. Bank Rakyat Indonesia Tbk for the period 2012-2019.
\end{abstract}

Keywords: Credit Risk (Non Performing Loan), Profitability (Return On Asset) 


\section{PENDAHULUAN}

Perekonomian global pada saat ini masih mempengaruhi kinerja industri perbankan. Kondisi perekonomian dan perbankan pada tahun ini lebih baik dibandingkan dengan tahun sebelumnya. Sejumlah faktor dari domestik turut mendukung pertumbuhan industri perbankan. Melihat hal tersebut, bank-bank pemerintah menargetkan pertumbuhan di industri bervariasi hingga 15 persen karena adanya beberapa penilaian, baik pendukung nasional dan pengaruh ekonomi global, sektor perbankan menunjukkan konsolidasi yang berlanjut dan meningkatnya pertumbuhan kredit. (Rizky Alika: 2019). Bank adalah suatu badan usaha yang menghimpun dana dari masyarakat dalam bentuk simpanan seperti tabungan, giro, deposito yang kemudian dana yang terkumpul dari masyarakat disalurkan kembali ke masyarakat dalam bentuk kredit guna meningkatkan taraf hidup rakyat banyak. Di tengah persaingan pasar yang semakin tajam, bank harus mampu menjaga kepercayaan masyarakat dengan cara mempertahankan kinerja keuangan melalui rasio profitabilitas dengan menggunakan indikator Return On Asset (ROA). Return On Asset merupakan rasio antara laba sebelum pajak atau Earning Before Tax terhadap total asset.

Menurut Irham (2017: 135) menyatakan bahwa "rasio profitabilitas merupakan rasio yang mengukur efektivitas manajemen secara keseluruhan yang ditunjukkan oleh besar kecilnya tingkat keuntungan yang diperoleh dalam hubungannya dengan penjualan maupun investasi”. Return On Asset (ROA) sangat penting bagi bank karena ROA digunakan untuk mengukur efektivitas perusahaan dalam menghasilkan keuntungan dengan memanfaatkan aktiva yang dimilikinya. Semakin besar ROA menunjukkan kinerja perusahaan semakin baik, karena tingkat pegembalian (return) yang diperoleh semakin besar. Saat ini, masih ada perbankan yang belum mampu meningkatkan profitabilitasnya (ROA). Seperti yang diungkap oleh Lembaga Penjamin Simpanan (LPS) dalam tiga tahun terakhir tingkat profitabilitas perbankan terus menurun. Beberapa perbankan yang mengalami penurunan profitabilitasnya terdapat di salah satu Bank Umum yang ada di Indonesia. Ketua Dewan Komisioner LPS Halim Alamsyah menyebutkan, salah satu penyebab menurunnya profitabilitas bank akibat margin bunga yang lemah karena tren penurunan bunga kredit. Menurunnya profitabilitas perbankan karena melalui penurunan tingkat keuntungan dari asset (return on asset/ ROA) perbankan dalam tiga tahun terakhir. (Kumparan: 2017)

Berikut adalah data Return On Asset (ROA) pada PT. Bank Rakyat Indonesia Tbk periode 2012-2019.

Tabel 1. Return On Asset PT. Bank Rakyat Indonesia Tbk Periode 2012-2019

\begin{tabular}{|r|c|c|c|}
\hline \multirow{2}{*}{ Tahun } & Laba Sebelum Pajak (Rp) & Total Aset (Rp) & ROA (\%) \\
\hline 2012 & 56.537 .964 & 1.947 .509 .301 & $2,90 \%$ \\
\hline 2013 & 65.398 .533 & 2.299 .857 .397 & $2,84 \%$ \\
\hline 2014 & 75.663 .811 & 2.766 .445 .278 & $2,74 \%$ \\
\hline 2015 & 77.547 .660 & 3.260 .044 .459 & $2,38 \%$ \\
\hline 2016 & 80.608 .320 & 3.708 .119 .404 & $2,17 \%$ \\
\hline 2017 & 86.190 .085 & 4.188 .258 .305 & $2,06 \%$ \\
\hline 2018 & 99.321 .128 & 4.752 .730 .825 & $2,09 \%$ \\
\hline 2019 & 104.434 .598 & 5.290 .481 .588 & $1,97 \%$ \\
\hline
\end{tabular}

Sumber: Indonesia Stock Exchange (2019)

Pada tabel diatas merupakan Return On Asset PT. Bank Rakyat Indonesia Tbk Periode 20122019. Dapat dilihat bahwa return on asset pada PT. Bank Rakyat Indoensia Tbk terjadi penurunan setiap tahunnya. Return on asset terendah terletak pada tahun 2019 sebesar 1,97\% dan return on asset tertinggi dicapai pada tahun 2012 sebesar 2,90\%. Dari data tersebut menunjukkan PT. Bank Rakyat Indonesia Tbk mengalami kesulitan untuk menjaga stabilitas pertumbuhan return on asset setiap tahunnya. Fenomena ini yang mendorong dan menjadi motivasi peneliti untuk mengangkat PT. Bank Rakyat 
Indonesia Tbk sebagai lokasi penelitian.

Adapun penelitian terdahulu yang mendukung penelitian ini yang dilakukan oleh Herlina, Nugraha, Imas Purnamasari (2016) dengan judul "Pengaruh Risiko Kredit terhadap Profitabilitas" menunjukkan bahwa variable risiko kredit yang diukur dengan Non Performing Loan memiliki pengaruh negatif terhadap profitabilitas yang diukur dengan Return On Asset pada Bank Umum Swasta Nasional Devisa tahun 2010-2014.

Kemudian penelitian yang diteliti oleh Usep Deden Suherman (2016) dengan judul "Pengaruh Risiko Kredit terhadap Profitabilitas Bank Jabar Banten Syariah" menunjukkan bahwa risiko kredit secara signifikan berpengaruh negatif terhadap profitabilitas yang terjadi pada Bank Jabar Banten Syariah periode 2010-2015.

Kemudian penelitian yang diteliti oleh Komang Monica Cristina dan Luh Gede Sri Artini (2018) dengan judul "Pengaruh Likuiditas, Risiko Kredit, dan Dana Pihak Ketiga Terhadap Profitabilitas pada Bank Perkreditan Rakyat (BPR)" menunjukkan bahwa variabel likuiditas, risiko kredit dan dana pihak ketiga mempunyai pengaruh yang signifikan terhadap profitabilitas pada Bank Perkreditan Rakyat (BPR) di Kabupaten Gianyar.

\section{Tujuan Penelitian}

Berdasarkan perumusan masalah yang telah disebutkan pada latar belakang diatas, maka tujuan penelitian, antara lain:

1. Untuk mengetahui risiko kredit pada PT. Bank Rakyat Indonesia Tbk pada periode 2012-2019.

2. Untuk mengetahui profitabilitas pada PT. Bank Rakyat Indonesia Tbk pada periode 2012-2019.

3. Untuk mengetahui pengaruh risiko kredit terhadap profitabilitas pada PT. Bank Rakyat Indonesia Tbk pada periode 2012-2019.

\section{TINJAUAN PUSTAKA}

\section{A. Pengertian Perbankan}

Menurut UU No. 10 Tahun 1998 yang menyempurnakan UU No. 7 Tahun 1992 yang dimaksud dengan bank adalah badan usaha yang menghimpun dana dari masyarakat dalam bentuk simpanan dan menyalurkannya kepada masyarakat dalam bentuk kredit dan atau bentuk lainnya dalam rangka meningkatkan taraf hidup rakyat banyak.

\section{B. Pengertian Kredit Macet/ Non Performing Loan}

Menurut Ikatan Akuntan Indonesia PSAK No. 31 (2009), kredit macet (non performing loan) pada umumnya merupakan kredit yang pembayaran angsuran pokoknya dan atau bunganya telah lewat 90 hari atau lebih setelah jatuh tempo, atau kredit yang pembayarannya secara tepat waktu sangat diragukan.

\section{Pengertian Risiko Kredit}

Menurut Peraturan Bank Indonesia Nomor 11/25/PBI/2009 Tahun 2009, risiko kredit adalah risiko akibat kegagalan debitur dan/atau pihak lain dalam memenuhi kewajiban kepada bank.

Menurut Ikatan Bankir Indonesia (2016: 22) "risiko kredit merupakan risiko nasabah yang tidak dapat memenuhi kewajiban yang sudah jatuh tempo".

Dari pengertian diatas dapat disimpulkan bahwa, risiko kredit merupakan kemungkinan terjadinya kerugian yang dialami bank dikarenakan nasabah/debitur tidak mampu atau gagal membayar kewajiban/hutangnya baik pokok maupun bunga. 


\section{Pengertian Profitabilitas/ Return On Asset}

Menurut Kasmir (2017: 204) "Return On Asset merupakan rasio yang menunjukkan hasil (return) atas jumlah aktiva yang digunakan dalam perusahaan. ROA juga merupakan suatu ukuran efektifitas manajemen dalam mengelola investasinya".

Menurut V Wiratna Sujarweni (2017: 64) "Return On Asset merupakan rasio yang digunakan untuk mengukur kemampuan dari modal yang diinvestasikan dalam keseluruhan aktiva untuk menghasilkan keuntungan neto".

Berdasarkan pengertian diatas dapat disimpulkan bahwa ROA atau Return On Asset merupakan rasio keuangan perusahaan untuk mengukur kekuatan perusahaan dalam mendapatkan keuntungan atau laba sebelum pajak pada tingkat pendapatan, aset dan juga modal saham.

\section{METODE PENELITIAN}

\section{Jenis Penelitian}

Jenis penelitian yang digunakan dalam penelitian ini adalah penelitian kuantitatif dengan pendekatan deskriptif. Menurut Sugiyono (2019:206), "Metode deskriptif adalah metode yang digunakan untuk menganalisis data dengan cara mendeskripsikan atau menggambarkan data yang telah terkumpul sebagaimana adanya tanpa bermaksud membuat kesimpulan yang berlaku umum atau generalisasi". Penelitian ini menggunakan perumusan masalah asosiatif. Menurut Sugiyono (2019: 210), "Asosiatif adalah dugaan terhadap ada tidaknya hubungan secara signifikan antara dua variabel atau lebih".

\section{Metode Pengumpulan Data} berikut:

Dalam penelitian ini untuk pengumpulan data digunakan metode pengumpulan data sebagai

\section{Pengumpulan Dokumen}

Pengumpulan dokumen dengan cara mengumpulkan, mencatat dan menghitung data-data yang ada diperusahaan yang berhubungan dengan objek yang akan diteliti.

\section{Studi Kepustakaan}

Studi kepustakaan atau studi literatur merupakan salah satu teknik pengumpulan data yang diperoleh dari berbagai sumber seperti buku, jurnal, skripsi terdahulu dan internet yang dapat menunjang pelaksanaan penelitian. Tujuannya untuk memperoleh informasi dan pengetahuan serta teori-teori yang relevan dengan masalah yang diteliti.

\section{HASIL DAN PEMBAHASAN}

Berdasarkan hasil perhitungan variabel menggunakan alat analisis adalah sebagai berikut:

\section{Analisis Regresi Linier Sederhana}

Hasil pengolahan data analisis regresi linier sederhana menggunakan SPSS versi 2.6 diperoleh hasil sebagai berikut:

Tabel 2. Analisis Regresi Linier Sederhana

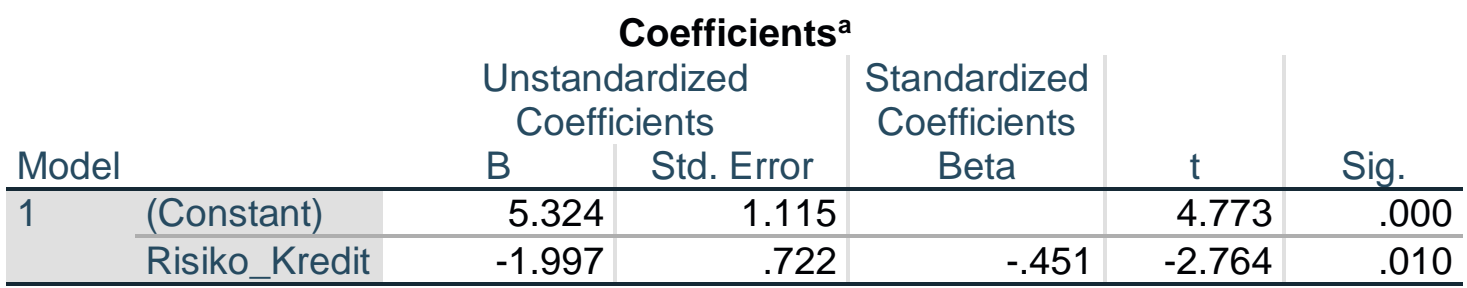

a. Dependent Variable: Profitabilitas

Sumber: SPSS versi 26

Pada tabel tersebut menunjukkan hasil perhitungan analisis regresi linier sederhana, maka persamaan regresi yang didapat adalah sebagai berikut:

$$
\mathrm{Y}=\mathbf{5 , 3 2 4}-\mathbf{1 , 9 9 7} \mathrm{X}
$$


Dari persamaan tersebut, maka dapat disimpulkan sebagai berikut:

1. Jika variabel risiko kredit $(\mathrm{X})$ nilainya adalah 0 , maka variabel profitabilitas $(\mathrm{Y})$ adalah 5,324

2. Persamaan regresi diatas menunjukkan nilai koefisien regresi (b) pada risiko kredit bertanda negatif (-) yang nilainya sebesar - 1,997. Artinya bahwa setiap kenaikan risiko kredit (X) 1\%, maka akan menurunkan profitabilitas sebesar 1,997.

\section{Analisis Korelasi Product Moment}

Hasil pengolahan data analisis korelasi product moment menggunakan SPSS versi 2.6 diperoleh hasil sebagai berikut:

Tabel 3. Analisis Korelasi Product Moment

\section{Correlations}

\begin{tabular}{|c|c|c|c|c|}
\hline & . & Risiko_Kredit & Profitabilitas & Sumber: \\
\hline Risiko_Kredit & Pearson & 1 & $-.451^{* *}$ & SPSS versi 26 \\
\hline & Sig. (2-tailed) & & .010 & \\
\hline & $\mathrm{N}$ & 32 & 32 & \\
\hline Profitabilitas & $\begin{array}{l}\text { Pearson } \\
\text { Correlation }\end{array}$ & $-.451^{* *}$ & 1 & \\
\hline & Sig. (2-tailed) & .010 & & \\
\hline & $\mathrm{N}$ & 32 & 32 & \\
\hline
\end{tabular}

Keterangan:

$\mathrm{X}=$ Risiko Kredit

$\mathrm{Y}=$ Profitabilitas

Berdasarkan persamaan diatas, diperoleh nilai koefisien korelasi risiko kredit terhadap profitabilitas sebesar $(r)=-0,451$. Dari hasil diatas, maka menunjukkan bahwa adanya korelasi negatif antara variabel risiko kredit dan variabel profitabilitas, artinya setiap kenaikan variabel risiko kredit akan diikuti penurunan variabel profitabilitas dan hasil perhitungan tersebut menunjukkan kategori hubungan "sedang" karena pada interval 0,40-0,599.

\section{Analisis Koefisien Determinasi}

Hasil perhitungan analisis koefisien determinasi menggunakan SPSS versi 2.6 diperoleh hasil sebagai berikut:

Tabel 4. Analisis Koefisien Determinasi

\begin{tabular}{ll|l|l|r} 
& \multicolumn{4}{c}{ Model Summary } \\
Model & $R$ & R Square & Adjusted R & Std. Error of \\
\hline 1 & $.451^{\mathrm{a}}$ & .203 & .176 & .92318 \\
\hline
\end{tabular}

a. Predictors: (Constant), Risiko_Kredit

Sumber: SPSS

versi 26

Berdasarkan tabel diatas, dapat diketahui koefisien determinasi sebesar 0,203 sama dengan 20,3\%. Angka tersebut mengandung arti bahwa variabel profitabilitas (X) dipengaruhi oleh variabel risiko kredit (Y). Sedangkan sisanya 79,7\% dipengaruhi oleh variabel diluar model regresi 


\section{Uji}

Hasil pengujian uji t pengaruh risiko kredit terhadap profitabilitas yang dilakukan dengan uji satu pihak atau uji pihak kiri. Berikut hasil uji t menggunakan SPSS versi 2.6, yaitu:

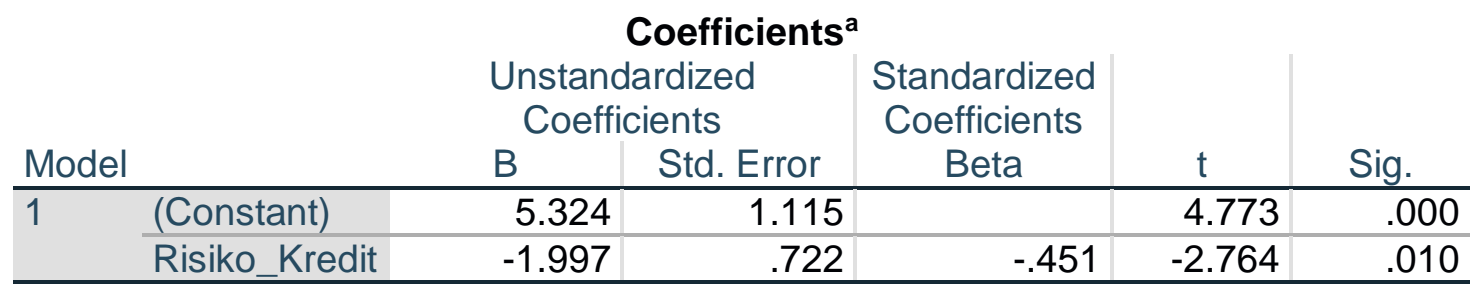

a. Dependent Variable: Profitabilitas

Tabel 5. Pengujian Hasil Hipotesis (Uji t)

Sumber: SPSS versi 26

Berdasarkan tabel tersebut, hasil pengujian hipotesis (uji t) satu pihak di atas menunjukan bahwa $\mathrm{t}_{\text {hitung }}$ sebesar $-2,764$. Dengan melihat $\mathrm{t}_{\text {tabel }}$ pada jumlah data $\mathrm{n}=32$ dan $\mathrm{df}=\mathrm{n}-\mathrm{k}=32-$ $2=30$ pada tingkat kesalahan $(\alpha)=5 \%$ diperoleh nilai $t_{\text {tabel }}$ sebesar 1,697 dan tingkat signifikansi $<0,05$, artinya Ho ditolak dan Ha diterima. Sehingga dapat disimpulkan bahwa risiko kredit (X) berpengaruh negatif dan signifikan terhadap profitabilitas $(\mathrm{Y})$.

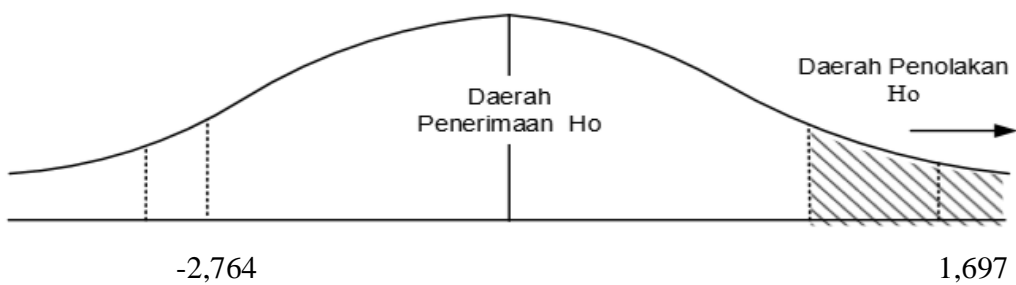

Gambar 1. Uji Pihak Kanan Pengaruh Risiko Kredit Terhadap Profitabilitas

Risiko kredit pada penelitian ini menggunakan indikator Non performing loan, dimana hasil penelitian menunjukkan bahwa adanya pengaruh negatif dan signifikan risiko kredit terhadap profitabilitas. Hasil penelitian ini didukung oleh hasil penelitian yang dilakukan oleh Herlina, Nugraha, Imas Purnamasari (2016). Risiko kredit memiliki pengaruh negatif terhadap profitabilitas, yang artinya setiap terjadi kenaikan NPL akan menyebabkan penurunan profitabilitas, sedangkan jika NPL terjadi penurunan maka menyebabkan profitabilitas bank naik.

Hasil penelitian ini juga didukung oleh Usep Deden Suherman (2016). Hasil penelitian ini menyatakan bahwa risiko kredit secara signifikan berpengaruh negatif terhadap profitabilitas. Dimana jika risiko kredit semakin besar, maka akan menurunkan profitabilitas yang artinya return pada bank akan menurun. Kemudian hasil penelitian ini didukung juga oleh Komang Monica Cristina dan Luh Gede Sri Artini (2018). Hasil penelitian tersebut menunjukkan bahwa risiko kredit berpengaruh negatif dan signifikan terhadap profitabilitas, jika risiko kredit yang dihadapi meningkat, maka profitabilitas yang dicapai juga akan menurun. 


\section{KESIMPULAN DAN SARAN}

\section{A. Kesimpulan}

Berdasarkan hasil penelitian yang dilakukan oleh peneliti mengenai pengaruh risiko kredit terhadap profitabilitas pada PT. Bank Rakyat Indonesia Tbk periode 2012-2019 dan pembahasan masalah yang sudah dipaparkan pada bab sebelumnya maka dapat ditarik kesimpulan sebagai berikut:

1. Risiko kredit pada PT. Bank Rakyat Indonesia Tbk pada tahun 2012-2019 mengalami fluktuasi dikarenakan jumlah kredit macet yang terus meningkat yang disebabkan oleh nasabah yang sengaja tidak membayar pokok atau bunga pinjaman yang sudah lebih dari jatuh tempo.

2. Profitabilitas pada PT. Bank Rakyat Indonesia Tbk pada tahun 2012-2019 yang dihitung dengan Return On Asset cenderung mengalami penurunan setiap tahunnya karena adanya penurunan kinerja laba sebelum pajak dan disebabkan oleh tingginya rasio kredit macet.

3. Berdasarkan hasil penelitian yang dilakukan menunjukkan adanya pengaruh negatif dan signifikan risiko kredit terhadap profitabilitas pada PT. Bank Rakyat Indonesia Tbk periode 2012-2019.

\section{B. Saran}

Berdasarkan hasil pengujian dan penelitian yang dilakukan oleh peneliti mengenai pengaruh risiko kredit terhadap profitabilitas, peneliti memberikan saran sebagai berikut:

1. Bagi pihak bank sebaiknya untuk kedepannya dapat melakukan evaluasi dalam kegiatan pemberian kredit agar dapat meminimalisir terjadinya risiko kredit dan dapat meningkatkan profitabilitasnya.

2. Bagi penelitian selanjutnya, peneliti mengharapkan jika mengambil topik bahasan yang sama agar menambahkan variabel selain risiko kredit yang diduga signifikan dan melakukan pengembangan penelitian agar dapat memberikan hasil yang lebih baik.

\section{DAFTAR PUSTAKA}

Irham. 2017. Analisis Laporan Keuangan. Bandung: Alfabeta

Kasmir, 2017. Analisis Laporan Keuangan. Depok: Rajawali Pers

Miranda, Febri Cyndi. 2019. Analisis Profitabilitas dan Aktivitas untuk Mengukur Kinerja Keuangan

Pada PT. Kawasan Industri Medan. Medan: Universitas Muhammadiyah Sumatera Utara

Ikatan Bankir Indonesia. 2016, Tata Kelola Manajemen Risiko Perbankan. Gramedia Pustaka Utama

Bank Indonesia. 2009. Peraturan Bank Indonesia No. 11/25/PBI/2009 tentang Penerapan Manajemen Risiko Bagi Bagi Bank Umum

Endang. 2015. Analisis Pengakuan Akuntansi Kredit Usaha Rakyat Bermasalah Pada Bank Rakyat Indonesia Cabang Sekayu. Jurnal Akuntansi. Volume 3. No. 2. Desember 2015

Situs web:

(https://katadata.co.id/berita/2019/01/15/kondisi-perekonomian-lebih-baik-himbara-targetkanpertumbuhan-12-15, diakses 10 April 2020)

(https://m.kumparan.com/amp/kumparannews/lps-ungkap-penyebab-profitabilitas-bank-terusmenurun, diakses 11 April 2020) 